\title{
Dietary patterns and glycemic indexes in type 2 diabetes patients
}

\section{Padrões alimentares e níveis glicêmicos de pacientes com diabetes tipo 2}

\author{
Elainy Peixoto Mariano STUDART ${ }^{1}$ (D) 0000-0002-0199-1139 \\ Soraia Pinheiro Machado ARRUDA ${ }^{1}$ (D) 0000-0002-3918-4738 \\ Helena Alves de Carvalho SAMPAIO ${ }^{1}$ (D) 0000-0001-8009-6898 \\ Tatiana Uchôa PASSOS ${ }^{1}$ (D) 0000-0002-7604-5948 \\ Antonio Augusto Ferreira CARIOCA ${ }^{1}$ (D) 0000-0002-1194-562X
}

\section{A B S T R A C T}

\section{Objective}

To identify the main dietary patterns in type 2 diabetes patients and study their association with glycemic indexes.

\section{Methods}

This is a cross-sectional study carried out in a diabetes treatment reference institution located in the city of Fortaleza (CE). Two R24h were applied, as well as $12 \mathrm{~h}$ fast blood glucose tests and anthropometric assessments in 188 diabetic patients. The principal components factor analysis method was applied together with a Varimax orthogonal rotation method to identify dietary patterns. The Poisson Regression and the Spearman coefficient were used to test the association with glycemic indexes.

\footnotetext{
1 Universidade Estadual do Ceará, Centro de Ciências da Saúde, Programa de Pós-Graduação em Saúde Coletiva. Av. Dr. Silas Munguba, 1700, Campus do Itaperi, 60741-000, Fortaleza, CE, Brasil. Correspondência para/Correspondence to: EPM STUDART. E-mail: <elainymariano@hotmail.com>.

2 Universidade de São Paulo, Centro de Ciências da Saúde, Departamento de Nutrição. São Paulo, SP, Brasil.

Support: Ministério da Ciência, Tecnologia e Inovação/Conselho Nacional de Desenvolvimento Científico e Tecnológico/Ministério da Saúde/Secretaria de Ciência, Tecnologia e Insumos Estratégicos - Decit no 07/2013 - Política Nacional de Práticas Integrativas e Complementares no Sistema Único de Saúde - área de Plantas Medicinais e Fitoterapia.

Article based on the master's thesis of EPM STUDART, entitled "Padrões alimentares e associação com níveis glicêmicos e perfil lipídico de pacientes diabéticos tipo 2”. Universidade Estadual do Ceará; 2017.
}

Como citar este artigo/How to cite this article

Studart EPM, Arruda SPM, Sampaio HAC, Passos TU, Carioca AAF. Dietary patterns and glycemic indexes in type 2 diabetes patients. Rev Nutr. 2018;31(1):1-12. https://doi.org/10.1590/1678-98652018000100001 


\section{Results}

A hundred eighty eight diabetic patients were evaluated, of which $51.1 \%$ patients had decompensated glucose values. Five main dietary patterns were identified: traditional Brazilian, energy-dense, infusion and wholegrain cereal, sandwich and dairy, and healthy diets, which explained $37.2 \%$ of the total variance in intake. A negative correlation with glucose was found for the traditional Brazilian diet $(p=0.018 ; r=-0.173)$.

\section{Conclusion}

Out of the five identified dietary patterns consumed by the type 2 diabetes patients studied, a higher adherence to the traditional Brazilian dietary patterns resulted in lower blood glucose levels.

Keywords: Blood Glucose. Diabetes Mellitus. Feeding behavior.

\section{RE S U M O}

\section{Objetivo}

Este estudo tem como objetivo identificar os principais padrões de consumo alimentar de pacientes diabéticos tipo 2, bem como investigar sua associação com níveis glicêmicos.

\section{Métodos}

Trata-se de um estudo transversal realizado em uma instituição de referência no tratamento do diabetes na cidade de Fortaleza (CE). Foi realizada aplicação de dois $R 24 h$, bem como aferição de glicemia de jejum de $12 \mathrm{~h}$ e medidas antropométricas em 188 pacientes diabéticos. Foi utilizado o método de Análise fatorial por Componentes Principais e rotação ortogonal Varimax para identificação dos padrões alimentares. Regressão de Poisson e coeficiente de correlação de Spearman foram utilizados para testar a associação com os níveis glicêmicos.

\section{Resultados}

Foram avaliados 188 pacientes diabéticos, dos quais 51,1\% apresentaram valores de glicemia descompensada. Foram identificados cinco principais padrões alimentares - tradicional brasileiro; denso em energia; infusões e cereais integrais; sanduíches e lácteos; e saudável - os quais explicaram 37,2\% da variância total de ingestão. O padrão tradicional brasileiro apresentou correlação negativa com os níveis glicêmicos ( $p=0,018$; $r=-0,173$ ).

\section{Conclusão}

Dos cinco padrões identificados como consumidos pelos diabéticos tipo 2 estudados, a maior adesão ao padrão tradicional brasileiro indicou menores níveis glicêmicos.

Palavras-chave: Glicemia. Diabetes Mellitus. Comportamento alimentar.

\section{NTRODUCTION}

The incidence of diabetes has progressively increased in the world, and to a greater extent in developing countries $[1,2]$, as the prevalence of diabetes affected more than 300 million people in 2013 [3].

Type 2 diabetes is characterized as being a disturbance in the efficient metabolism of glucose and it is related to a considerable increase in the risk of cardiovascular diseases, which can lead to serious complications [3].
Most people with this type of diabetes are overweight or obese and do not rely on exogenous insulin to survive, but may require its use only as a treatment for metabolic control [4].

Genetic conditions do play an important role for the development of the disease, but the current epidemic indicates changes in lifestyle. Overweight and obesity are considered important risk factors for Type 2 diabetes, which result from imbalanced food intake and caloric expenditure often due to an unhealthy lifestyle, 
insufficient physical exercise, and unhealthy food consumption $[1,5]$. These facts show that environmental elements are the main causes of the increase of type 2 diabetes $[4,6]$.

It is evident that the diet is one of the main risk factors that modifies other risk factors [7]. With the onset of diabetes, food choice and eating habits play a crucial role in controlling disease progression [8].

In traditional epidemiology, the main nutritional approach is to investigate the nutrients or food and their relationship with chronic diseases, including diabetes. However, the human diet is complex, since foods are not consumed in isolation and the nutrients operate in a synergistically or inhibitory way, making it difficult to detect these possible associations. This fact justifies the global consideration of the use of dietary patterns as an alternative to overcome these limitations, analyzing the effects of multiple dietary factors on the individual's health $[7,9]$.

Thus, it is important to know the eating patterns of diabetic individuals and their association with clinical aspects of the disease. In Brazil, we have not found any studies that analyze the dietary patterns among diabetics, nor their relationship with glycemic control.

In this context, the aim of the present study was to identify the main eating consumption patterns of type 2 diabetic patients and investigate their association with glycemic levels.

\section{METHODS}

This cross-sectional study was carried out at an important diabetes treatment institution that receives patients from the Sistema Único de Saúde (SUS, Unified Health System), in Fortaleza (CE).

The study population consisted of 188 diabetic female and male patients; patients with type 2 diabetes Mellitus diagnosed more than 2 years ago (thus, identifying the glycemic control of the individuals); the patients were continuously monitored at the institution; adults or elderly (age $\geq 20$ years); Body Mass Index (BMI) of $25.0-34.9 \mathrm{~kg} / \mathrm{m}^{2}$; use of oral hypoglycemic agentes such as metformin hydrochloride, glibenclamide and/or glicazide, which are distributed by SUS; and they were not on insulin; The patients were not affected by other known diseases, except those commonly associated with type 2 diabetes Mellitus (hypertension, dyslipidemia, diabetic dermopathy, among others). Since many diabetics are overweight, the BMI was standardized because advanced obesity has more negative metabolic consequences than overweight [9] and obesity grade I.

The research was approved by the Research Ethics Committee of Universidade Estadual do Ceará (UECE) under report CAAE $n^{\circ}$ 30308114.1.0000.5534. The interviews were carried out through a semi-structured form, containing data related to sex, age, race (selfreported), years of education, occupation, monthly income, use of medications, and known health problems.

The 24-hour food recall (R24h) and 12-h fasting glycemia were evaluated using the Alere Cholestech LDX ${ }^{\circledast}$ device (Alere, São Paulo, São Paulo, Brasil) and anthropometric measurements of weight, height, and waist circumference. Two R24h were used, one being collected during the interview and the other one was filled out on a weekend day and collected by telephone [10].

According to the American Diabetes Association (ADA) [11], glycemic levels are considered controlled when values are lower than $130 \mathrm{mg} / \mathrm{dL}$ for fasting glycemia and uncontrolled when they are equal to or greater than $130 \mathrm{mg} / \mathrm{dL}$.

The data collected by home measurements through the R24h were then converted to grams or milliliters using a specific table [12]. The foods were listed and grouped, taking into consideration the nutritional composition, to reduce the number of dietary variables, since this food survey allows an unlimited number of 
items to be listed. The adjusted mean weight by the intra-individual variance of the two R24h was then calculated by the Multiple Source Method (MSM), which represented the dietary variable used in the analysis to identify the dietary patterns.

The Principal Component exploratory factorial Analysis (PCA) was used, followed by Varimax orthogonal rotation, to identify the dietary patterns of the group studied.

This analysis collected the food variables based on the degree to which they are related to each other and the scores for each factor allows the categorization into groups, such as quartiles. This technique is widely used to reduce data and build a theory [13].

Bartlett's sphericity test and the KaiserMeyer-Olkin coefficient (KMO) were carried out at a cut-off value of $p \leq 0.05$ and $K M O \geq 0.50$, respectively [14-16], indicating satisfactory level of confidence for the factorial analysis.

The criteria that determined the number of factors retained were the components with eigenvalues higher than 1.0, Cattel scree plot, in which the number of points on the more declined determine the appropriate number of factors to be retained, and the conceptual significance of the patterns was identified [13]. After establishing the factors, they were rotated by the Varimax method.

The principal components were formed as the foods presented important factorial loads, established at $\geq 0.3$ (indicating direct correlation with the pattern) or $\leq-0.3$ (inverse correlation with the pattern) [17]. In nutritional epidemiology, these techniques aim at building linear combinations of food intake to explain the high rate of variation in food consumption in general [13].

The nutritional composition of the foods in each component were determinant for their appointment and denominations previously used in other studies were prioritized when the composition pattern was similar.
Each individual received a score for each principal component. These were categorized into quartiles and the upper quartile indicated greater adherence to the dietary pattern.

Statistical analysis was performed using the Stata program, version 12.0. (Stata Corporation, College Station, Texas, United States) Initially, descriptive analysis of the data was performed, the categorical variables were presented in simple and percentage frequencies, and numerical variables presented as means (standard deviation) or median (interquartile range), which were determined by the Shapiro-Wilk test that tested the normality of these variables.

To evaluate the association between the dietary patterns and glycemic levels, a Poisson regression with robust variance estimation was used, which indicated the Prevalence Ratios (PR) of independent variables (dietary patterns) in relation to the outcomes, and classified the dependent variable (glycemic level) as dichotomous: controlled and uncontrolled. Bivariate and multivariate analyses were carried out. The multivariate analysis was verified by two adjusted analyses, one for sociodemographic data (education, income, age and sex) (model I) and the other one for nutritional status (model II).

Spearman's correlation coefficient was used to verify the correlation between the factorial scores (quartiles) in each pattern and blood glucose levels. Estimates were measured by points and intervals with $95 \%$ confidence and at a $5 \%$ significance level.

RES U L T S

The study sample consisted of 188 diabetics, of which $56.9 \%$ were elderly and $51.1 \%$ were men. The mean age of the individuals was 61 years $( \pm 9.09)$, with a median income of 2.8 minimum wages (1.9-4.0) and $49.2 \%$ of them had not completed high school.

The median BMI of the group was $29.0 \mathrm{~kg} / \mathrm{m}^{2}(27.7-31.0)$ and frequencies of $65.4 \%$ overweight and $34.6 \%$ of obesity grade । 
were found. The median Waist Circumference (WC) for men was $103.5 \mathrm{~cm}(98-106.3)$ and for women $99 \mathrm{~cm}$ (96-104) of the diabetics studied, $76.5 \%$ presented waist circumference above the normality parameters (Table 1).

In addition to diabetes, other pathologies diagnosed were: hypertension, Cardiovascular Disease (CVD), dyslipidemia, hypothyroidism, arthrosis, neuropathy, depression, fibromyalgia, gastritis, glaucoma, labyrinthitis, diverticulitis, and renal failure. The most common drugs administered were hypoglycemic agents (glibenclamide, gliclazide, metformin, glifage, glimepiride, diamicron, galvus), antihypertensives (atenolol, enalapril, ramipril, captopril, losartan, amlodipine, natrilix), statins (atorvastatin, simvastatin), diuretics (hydrochlorothiazide, furosemide), among others such as aspirin and omeprazole.

After confirming the adequacy of the data by the KMO coefficient (0.5) and Bartlett's

Table 1. Anthropometric and socioeconomic characteristics of the type 2 diabetic patients interviewed. Fortaleza (CE), Brazil, 2017.

\begin{tabular}{|c|c|c|c|}
\hline Variables & $\mathrm{n}$ & $\%$ & Mean/Median \\
\hline \multicolumn{4}{|l|}{ Sex } \\
\hline Men & 96 & 51.1 & \\
\hline Women & 92 & 48.9 & \\
\hline Age (years) & & & $61( \pm 9.09)$ \\
\hline \multicolumn{4}{|l|}{ Age group } \\
\hline Adults & 81 & 43.1 & \\
\hline Elderly & 107 & 56.9 & \\
\hline \multicolumn{4}{|l|}{ Ethnicity (self-reported) } \\
\hline White & 32 & 17 & \\
\hline Brown & 113 & 60.1 & \\
\hline Black & 38 & 20.2 & \\
\hline Not reported & 5 & 2.7 & \\
\hline BMI $\left(\mathrm{kg} / \mathrm{m}^{2}\right)$ & & & $29.0(27.7-31.0)$ \\
\hline \multicolumn{4}{|l|}{ BMI classification } \\
\hline Overweight & 123 & 65.4 & \\
\hline Obesity grade I & 65 & 34.6 & \\
\hline \multicolumn{4}{|l|}{$W C(\mathrm{~cm})$} \\
\hline Men & & & $103.5(98.0-106.2)$ \\
\hline Wowen & & & $99(96-104)$ \\
\hline Income (MW) & & & $2.8(1.9-4.0)$ \\
\hline \multicolumn{4}{|l|}{ Education } \\
\hline Completed high school or university degree & 96 & 50.8 & \\
\hline Did not complete high school & 92 & 49.2 & \\
\hline \multicolumn{4}{|l|}{ Occupations } \\
\hline Retired & 76 & 40.4 & \\
\hline Housekeeper & 24 & 12.8 & \\
\hline Self employed & 8 & 4.2 & \\
\hline Merchant & 8 & 4.2 & \\
\hline Daily wages & 8 & 4.2 & \\
\hline Public service & 6 & 3.2 & \\
\hline Graduate profession & 6 & 3.2 & \\
\hline Others & 52 & 27.8 & \\
\hline
\end{tabular}

Note: BMI: Body Mass Index; MW: Merriam-Webter; WC: Waist Circumference. 
sphericity test $(p<0.001)$, the 24 food groups that were included in the analysis (Chart 1) resulted in five identified eating patterns, which were denominated as follows: traditional Brazilian, energy-dense, infusion and whole grain cereal, sandwich and dairy, and healthy dietary patterns, which together explained $37.2 \%$ of the total variance in intake.

Foods in the traditional Brazilian pattern were those that are most commonly consumed by the Brazilian population, such as rice, beans and poultry (with negative load for regional foods in the northeast). The energy-dense pattern was composed of processed beverages, biscuits and cakes, sweets and pasta with a negative load for soups and broths. The infusion and whole grain pattern included sweetener, coffee and infusions and whole grain cereals with a negative load for bovine and pork, eggs and smoothies. The sandwich and dairy pattern consisted of beef and pork, dairy and porridges, white bread and fats. The healthy pattern was composed of foods such as oil and oilseeds, fruits and natural juices, roots and tubers and vegetables with a negative load for ultra-processed foods (Table 2).

A total of 96 individuals (51.1\%) presented uncontrolled glycemia, with a median value of

Chart 1. Food distribution in each group. Fortaleza (CE), Brazil, 2017.

\begin{tabular}{|c|c|}
\hline Food groups & Food \\
\hline Sweetening & Sweeteners \\
\hline Rice & White rice, rice with milk, parboiled rice. \\
\hline Poultry & Chicken, roasted turkey, chicken, vatapá. \\
\hline Oils and oilseeds & Olive oil, peanuts, nuts. \\
\hline Industrialized beverages & Soft drinks, industrialized juices. \\
\hline Biscuits and cakes & Sweet biscuits, salty biscuits, fried cake, cake without filling, broccoli, arrowroot biscuit, cake \\
\hline Coffee and infusions & Coffee, tea. \\
\hline Beef and pork & Beef, pork, viscera. \\
\hline Whole grains & Barley, brown rice, oats, cereal bar, chia, granola, flaxseed, whole wheat bread. \\
\hline Regional Foods & $\begin{array}{l}\text { Beans and rice, couscous, flour, corn on the cob, mungunzá, paçoca, pamonha, pirão, tapioca, } \\
\text { canjica, popcorn. }\end{array}$ \\
\hline Sweets & Chocolate powder, sugar, filled biscuits, cake with filling, chocolate, churros, jam, gelatin, ice cream. \\
\hline Beans & Feijoada, beans. \\
\hline Fruits and natural juices & $\begin{array}{l}\text { Avocado, pineapple, açaí, plum, banana, cashew, kaki, guava, kiwi, orange, lemon, apple, papaya, } \\
\text { mango, watermelon, melon, strawberry, noni, pear, sapoti, tangerine, grape, water coconut, and } \\
\text { natural juices. }\end{array}$ \\
\hline Fats & Sauce, mayonnaise, butter, margarine, pate. \\
\hline Dairy products and porridge & $\begin{array}{l}\text { Skim curd, skimmed yogurt, soymilk, skim milk, white cheese, light curd cheese, whole curd, yogurt, } \\
\text { whole milk, cream, cheese, traditional curd, sour cream, porridge. }\end{array}$ \\
\hline Pasta & Macaroni, pasta, fried pasta, pizza, salted snacks, sandwich, natural sandwich. \\
\hline Egg & Egg, omelet, eggnogg. \\
\hline White bread & Toast, bread. \\
\hline Fish and seafood & Shrimp, fish, seafood. \\
\hline Roots and tubers & Potato, sweet potato, beetroot, carrot, manioc, potato chips. \\
\hline Soups and broths & Risotto, soups, and broths. \\
\hline Ultra-processed & $\begin{array}{l}\text { Canned olive, processed meat, sausages, canned corn, canned peas, coconut milk, 3-minute pasta, } \\
\text { canned fish, microwave popcorn, ketchup, industrialized snacks. }\end{array}$ \\
\hline Vegetables & $\begin{array}{l}\text { Garlic, vinaigrette, zucchini, broccoli, onion, green odor, chuchu, gherkin, cucumber, chili, okra, } \\
\text { pumpkin, tomato, chard, lettuce, cauliflower, cabbage butter, spinach, cabbage, arugula. }\end{array}$ \\
\hline Fruit smoothy & Smoothies. \\
\hline
\end{tabular}


Table 2. Distribution of the factorial load of main eating patterns identified in type 2 diabetics. Fortaleza (CE), Brazil, 2017.

\begin{tabular}{|c|c|c|c|c|c|}
\hline \multirow{2}{*}{ Food groups } & \multicolumn{5}{|c|}{ Eating patterns } \\
\hline & Traditional Brazilian & Energy-dense & Infusions and whole grains & Sanduich and dairy & Healthy \\
\hline Rice & 0.700 & & & & \\
\hline Poultry & 0.686 & & & & \\
\hline Beans & 0.603 & & & & \\
\hline Regional foods & -0.443 & & & & \\
\hline Industrial beverages & & 0.743 & & & \\
\hline Sweets & & 0.638 & & & \\
\hline Pasta & & 0.519 & & & \\
\hline Biscuits and cakes & & 0.364 & & & \\
\hline Soups and broths & & -0.346 & & & \\
\hline Whole grains & & & 0.622 & & \\
\hline Coffee and infusions & & & 0.390 & & \\
\hline Sweetener & & & 0.350 & & \\
\hline Beef and pork & & & -0.460 & & \\
\hline Egg & & & -0.452 & & \\
\hline Fruit smoothy & & & -0.335 & & \\
\hline Fats & & & & 0.802 & \\
\hline White bread & & & & 0.640 & \\
\hline Beef and pork & & & & 0.415 & \\
\hline Dairy and porridge & & & & 0.301 & \\
\hline Vegetables & & & & & 0.650 \\
\hline Roots and tubers & & & & & 0.499 \\
\hline Oil and oilseeds & & & & & 0.401 \\
\hline Fruits and natural juices & & & & & 0.350 \\
\hline Ultra-processed & & & & & -0.460 \\
\hline Variance Explained (\%) & 7.89 & 7.49 & 7.41 & 7.36 & 7.08 \\
\hline Eigenvalue & 2.09 & 1.96 & 1.78 & 1.61 & 1.49 \\
\hline
\end{tabular}

Note: Foods with factorial load $\geq 0.3$ and $\leq-0.3$; Total variance: $37.2 \%$.

$131 \mathrm{mg} / \mathrm{dL}$ (109.5-152.5). The glycemic values were negatively correlated only with the traditional Brazilian pattern ( $p=0.018 ; r=-0.173$ ) (Table 3 ).

No associations between adherence to dietary patterns and the glycemic level category were observed in the bivariate and multivariate association analyses, and adjustment models I and II (Table 4).

\section{DISCUSSION}

In the present study, five main eating patterns of the diabetics (traditional Brazilian,
Table 3. Correlation between glycemic levels and dietary patterns of type 2 diabetic patients. Fortaleza (CE), Brazil, 2017.

\begin{tabular}{lcc}
\hline Patterns & $r$ & $p$ \\
\hline Traditional Brazilian & -0.173 & 0.018 \\
Energy-dense & -0.028 & 0.704 \\
Infusions and whole grains & 0.018 & 0.810 \\
Sandwich and Dairy & 0.125 & 0.087 \\
Healthy & 0.105 & 0.151 \\
\hline
\end{tabular}

Note: r: Spearman's correlation coefficient.

energy-dense, infusion and whole grain, sandwich and dairy, and healthy diets) were 
Table 4. Unadjusted and adjusted Prevalence Ratio (PR) and Confidence Interval (95\% Cl) for the association between glycemia and eating patterns in type 2 diabetic patients. Fortaleza (CE), Brazil, 2017.

\begin{tabular}{|c|c|c|c|c|c|}
\hline \multirow{2}{*}{ Eating pattern } & \multicolumn{5}{|c|}{ Glycemia } \\
\hline & & $(\%)$ & Unadjusted PR $(95 \% \mathrm{Cl})$ & Adjusted PR $(95 \% \mathrm{CI})^{*}$ & Adjusted PR $(95 \% \mathrm{CI})^{* *}$ \\
\hline Traditional Brazilian & & & $p=0.204$ & $p=0.128$ & $p=0.262$ \\
\hline Q1 & 28 & $(59.6)$ & Reference & Reference & Reference \\
\hline Q2 & 27 & $(57.4)$ & $0.99(0.87-1.12)$ & $1.00(0.88-1.15)$ & $1.00(0.87-1.14)$ \\
\hline Q3 & 22 & $(46.8)$ & $0.92(0.81-1.05)$ & $0.91(0.80-1.04)$ & $0.92(0.81-1.05)$ \\
\hline Q4 & 19 & $(40.4)$ & $0.88(0.77-1.01)$ & $0.88(0.77-1.00)$ & $0.89(0.78-1.02)$ \\
\hline Energy-dense & & & $p=0.290$ & $p=0.401$ & $p=0.535$ \\
\hline Q1 & 27 & $(57.4)$ & Reference & Reference & Reference \\
\hline Q2 & 19 & $(40.4)$ & $0.89(0.78-1.02)$ & $0.90(0.79-1.03)$ & $0.92(0.80-1.05)$ \\
\hline Q3 & 27 & $(57.4)$ & $1.00(0.88-1.14)$ & $0.98(0.87-1.11)$ & $0.99(0.88-1.12)$ \\
\hline Q4 & 23 & $(48.9)$ & $0.95(0.83-1.08)$ & $0.92(0.80-1.06)$ & $0.93(0.81-1.07)$ \\
\hline Infusions and whole grains & & & $p=0.599$ & $p=0.729$ & $p=0.620$ \\
\hline Q1 & 22 & $(46.8)$ & Reference & Reference & Reference \\
\hline Q2 & 23 & $(48.9)$ & $1.01(0.88-1.16)$ & $1.00(0.87-1.15)$ & $1.00(0.87-1.15)$ \\
\hline Q3 & 23 & $(48.9)$ & $1.01(0.88-1.16)$ & $0.98(0.86-1.13)$ & $0.98(0.85-1.13)$ \\
\hline Q4 & 28 & $(59.6)$ & $1.09(0.95-1.24)$ & $1.06(0.92-1.21)$ & $1.07(0.93-1.22)$ \\
\hline Sanduich and dairy & & & $p=0.466$ & $p=0.595$ & $p=0.430$ \\
\hline Q1 & 20 & $(42.6)$ & Reference & Reference & Reference \\
\hline Q2 & 26 & $(55.3)$ & $1.09(0.95-1.25)$ & $1.08(0.94-1.24)$ & $1.10(0.97-1.26)$ \\
\hline Q3 & 23 & $(48.9)$ & $1.04(0.91-1.20)$ & $1.00(0.87-1.15)$ & $1.00(0.88-1.15)$ \\
\hline Q4 & 27 & $(57.4)$ & $1.10(0.97-1.26)$ & $1.05(0.92-1.20)$ & $1.05(0.92-1.20)$ \\
\hline Healthy & & & $p=0.529$ & $p=0.687$ & $p=0.585$ \\
\hline Q1 & 24 & $(51.1)$ & Reference & Reference & Reference \\
\hline Q2 & 20 & $(42.6)$ & $0.94(0.82-1.08)$ & $0.97(0.84-1.11)$ & $0.98(0.85-1.12)$ \\
\hline Q3 & 25 & $(53.2)$ & $1.01(0.89-1.16)$ & $1.03(0.90-1.19)$ & $1.05(0.91-1.20)$ \\
\hline Q4 & 27 & (57.4) & $1.04(0.91-1.19)$ & $1.05(0.91-1.21)$ & $1.07(0.93-1.23)$ \\
\hline
\end{tabular}

Note: "Prevalence ratio adjusted for sociodemographic factors (education, income, age group and sex); ${ }^{* *}$ Prevalence ratio adjusted for demographic factors (education, income, age and sex) and nutritional status (BMI). Poisson analysis with robust variance estimation; $P$ : trend value.

identified and an inverse correlation between glycemia and the traditional Brazilian pattern was observed, indicating that the higher the adherence to this dietary pattern, the lower the blood glucose values.

The so-called traditional Brazilian pattern was characterized by higher consumption of rice, poultry, and beans. In the literature researched no studies on the dietary patterns of type 2 diabetic patients. However, in a study of black and Hispanic American diabetics, the 'Caribbean' pattern was identified, which is characterized by the consumption of rice and Rioja beans, the one closest to the Brazilian diet [18]. Similar dietary patterns were found in Brazilian adults who consume rice and beans [14] along with other foods such as meat and margarine [19], but no association with glycemic levels was investigated.

The consumption of pasta and sweets, as found in the energy-dense dietary pattern (industrialized beverages, sweets, pastas, biscuits, and cakes), was also observed in the study of Davis [18], who described it as the "pizza and 
sweet" pattern that also included other foods such as bread, pizza, and fried chicken. In another study with Australian individuals with and without diabetes, a pattern called "sweet" dietary pattern (consumption of cake, biscuits, chocolate, ice cream, and sweets) was found [20].

In Brazil, a study with elderly people with hypertension discussed a similar denomination and diet composition that included sweets, soft drinks, and pasta, but also meat and viscera, which differ from the findings of the present study [15].

No studies with a pattern similar to the infusion and whole grain dietary pattern that included whole grains, coffee and infusions, or sweeteners in the same eating pattern were found. The presence of whole grains in eating patterns known as 'healthy' are usually mentioned [19,21], as well as coffee belonging to the so-called 'traditional' eating pattern $[14,15]$. These foods, particularly whole grains and sweeteners, are commonly recommended for diabetic patients, since their consumption contributes to the treatment of the disease due to the metabolic advantages of slow release of glycogen during the digestive process [22].

One study with Japanese diabetics determined a eating pattern called 'meat, fats and oils, seasonings and eggs' [23] and one with Korean diabetics identified as 'bread, meat and alcohol' pattern [21] were the ones that most resembled the sandwich and dairy dietary pattern including the consumption of fats, meats and bread in the same factor.

The so-called healthy pattern was composed of vegetables, roots and tubers, olive oil and oilseeds, fruits, and natural juices. In the literature, patterns with this same denomination are quite frequent. The food consumption of diabetic patients in Iran [24], the United States [18], and Australia [20] was similar to the healthy pattern in the present study, as they consumed fruits and vegetables within the same factor, as well as oilseeds and fish, which was also classified as a 'healthy' dietary pattern.

In other studies with the Brazilian population, we also found 'healthy' eating patterns similar to the ones in the present study, but they included more foods in the same pattern $[14,15,19]$.

Foods that are generally called 'healthy' patterns positively affect glucose metabolism, reduce insulin resistance, even in patients with type 2 diabetes, since they have been confirmed in other studies, and they are inversely associated with the incidence of type 2 diabetes $[25,26]$.

The explanation can be given through the beneficial effects of some nutrients widely found in healthy diets called plant-rich fruits such as fiber, antioxidants, unsaturated fatty acids and micronutrients, such as magnesium, in addition to the low saturated fat content has shown a direct improvement in postprandial glycemia as well as in long-term glucose metabolism [27].

A study in an Eastern Chinese cohort with a sample of type 2 diabetic individuals or those who presented altered fasting glycemia found an association only between the so-called pattern 'rich in vegetables' with diabetes and glycemic control. Thus, those who adhered to this dietary pattern presented improved fasting glucose control and lower risk of diabetes [28].

The epidemiological study with Japanese individuals, which also found an association between the adherence to a 'healthy' pattern and lower incidence of diabetes, emphasized that the diet significantly improves glucose metabolism when combined with a healthy lifestyle, such as the practice of physical activities, and the regular consumption of the dietary pattern [26]. This may partially explain why this association was not observed in the present study as the greatest adherence and food regularity was found in the traditional Brazilian pattern, probably due to customs and economic conditions. This pattern was the one that best explained the consumption variation 
in the group, while the healthy pattern was the one that least explained variation.

Thus, among the patterns identified in the present study, only the traditional Brazilian pattern was related to glycemic levels, and the higher the factorial score (greater adhesion) to this pattern, the lower the glycemia values. Although this pattern does not include foods identified as protectors, such as fruits and vegetables, it does contain low-fat foods, such as white meat, and bean fibers and essential amino acids found in beans and rice.

Thus, it may be assumed that individuals who follow more traditional habits consume less industrialized foods, rich in sugars and fats, which are usually associated with greater health hazards, and consequently diabetes. The highly industrialized diet is a trend in the Brazilian population [29], but we found that diabetic patients have a greater adherence to the more traditional dietary pattern.

Although it is recommended to adhere to a diet rich in vegetables and other protective foods for diabetes, the greater adherence to the traditional Brazilian pattern may have been influenced by the socioeconomic status of the individuals, since the food does not contain an excess of carbohydrates and fats and it is less expensive when compared to the so-called healthy pattern.

It is evident, therefore, that nutritional practice does not always follow the knowledge and nutritional guidelines of diabetic patients. There is often a gap between knowledge and practice [30].

The present study has some limitations. The cross-sectional design, which does not establish cause and effect; the use of the 24-hour food recall method to investigate consumption, which may be biased memory, in addition to leading patients to underestimate or overestimate consumption; and the identification method of eating patterns used in this study due to the subjectivity inherent to the process. Thus, it may not be concluded that the data can be generalized to a wide range of the population, even in patients with type 2 diabetes.

However, all measures to mitigate the impact of such limitations were taken, such as the detailed training of the interviewers and the detailed description, based on the literature, of the stages of analysis of the factorial components. The present study investigated the main dietary patterns in a group of type 2 diabetics in Brazil and its association with glycemic levels, which may contribute to explain the gaps in the research on the diet-diabetes relationship, a disease with a significant prevalence all around the world.

\section{CONCLUSION}

Five main eating patterns were identified among the type 2 diabetics studied (traditional Brazilian, energy-dense, infusion and whole grain, sandwich and dairy, and healthy diets). The traditional Brazilian pattern was inversely correlated with the glycemic levels, indicating that it can also be used as a protection standard for diabetics.

\section{CONTRIBUTIONS}

EPM STUDART Main author; conception; data collection, data interpretation and review. SPM ARRUDA data analysis and interpretation; review and approval of the final version. HAC SAMPAIO Review and approval of the final version of the article. TU PASSOS Data collection. AAF CARIOCA Data analysis and interpretation.

\section{REFERENCES}

1. Oggioni C, Lara J, Wells JCK, Soroka K, Siervo M. Shifts in population dietary patterns and physical inactivity as determinants of global trends in the prevalence of diabetes: An ecological analysis. Nutr Metab Cardiovasc Dis. 2014;24(10):1105-11.

2. Schmidt MI, Duncan BB, Mill JG, Lotufo PA, Chor D, Barreto SM, et al. Cohort profile: Longitudinal 
Study of Adult Health (ELSA-Brasil). J Epidemiol. 2015;44:66-75.

3. International Diabetes Federation. Diabetes atlas. Brussels: IDF; 2013.

4. Sociedade Brasileira de Diabetes. Diretrizes da Sociedade Brasileira de Diabetes: 2014-2015. Rio de Janeiro: Sociedade Brasileira de Diabetes; 2015.

5. Associação Brasileira para o Estudo da Obesidade e da Síndrome Metabólica. Diretrizes Brasileira de Obesidade. São Paulo: ABESO; 2016.

6. Alhazmi A, Stojanovski E, McEvoy M, Garg ML. The association between dietary patterns and type 2 diabetes: A systematic review and metaanalysis of cohort studies. J Hum Nutr Diet. 2013;27(3):251-60.

7. Frank LK, Kroger J, Schulze MB, Bedu-Addo G, Mockenhaupt FP, Danquah I. Dietary patterns in urban Ghana and risk of type 2 diabetes. Br J Nutr. 2014;112:89-98.

8. Colles SL, Singh S, Kohli C, Mithal A. Dietary beliefs and eating patterns influence metabolic health in type 2 diabetes: A clinic-based study in urban North India. Indian J Endocr Metab. 2013;17(6):1066-72.

9. Castro MBT, Sichieri S, Brito FSB, Nascimento S, Kac G. Mixed dietary pattern is associated with a slower decline of body weight change during postpartum in a cohort of Brazilian women. Nutr Hosp. 2014;29(3):519-25.

10. Molina MCB, Benseñor IM, Cardoso LO, Velasquez-Melendez G, Drehmer M, Pereira TSS. Reprodutibilidade e validade relativa do Questionário de Frequência Alimentar do ELSABrasil. Cad Saúde Pública. 2013;9(2):379-89.

11. American Diabetes Association. Standards of Medical Care in Diabetes: 2016. Diabetes Care: ADA; 2016.

12. Pinheiro ABV, Lacerda EMA, Benzecry, EH, Gomes MCS, Costa VM. Tabela para avaliação de consumo alimentar em medidas caseiras. 5a ed. São Paulo: Atheneu; 2005.

13. Newby PK, Tucker KL. Empirically derived eating patterns using factor or cluster analysis: A review. Nutr Rev. 2004;62(5):177-203.

14. Matos SMA, Barreto ML, Rodrigues LC, Oliveira VA, Oliveira LPM, D'Innocenzo S, et al. Padrões alimentares de crianças menores de cinco anos de idade residentes na capital e em municípios da Bahia, Brasil, 1996 e 1999/2000. Cad Saúde Pública. 2014;30:44-54.

15. Santos RO, Fisberg RM, Marchioni DM, Baltar VT. Dietary patterns for meals of Brazilian adults. $\mathrm{Br} J$ Nutr. 2015;114(5):822-8.
16. Adriano LS, Sampaio HAC, Arruda SPM, Portela CLM, Melo MLP, Carioca AAF, et al. Healthy dietary pattern is inversely associated with nonalcoholic fatty liver disease in elderly. $\mathrm{Br} \mathrm{J}$ Nutr. 2016;115(12):2189-95.

17. Hearty AP, Gibney MJ. Comparison of cluster and principal component analysis techniques to derive dietary patterns in Irish adults. $\mathrm{Br} \mathrm{J}$ Nutr. 2008;101(4):598-608.

18. Davis NJ, Schechter CB, Wylie-Rosett J, Walker EA, Ortega $F$, Rosen $R$, et al. Dietary patterns in blacks and Hispanics with diagnosed diabetes in New York City's South Bronx. Am J Clin Nutr. 2013;97(4):878-85.

19. Arruda SPM, Silva AAM, Kac G, Goldani MZ, Bettiol $H$, Barbieri MA. Socioeconomic and demographic factors are associated with dietary patterns in a cohort of young Brazilian adults. BMC Public Health. 2014; 14:654-67.

20. Dipnall JF, Pasco JA, Meyer D, Berk M, Williams $\mathrm{L}$, Dodd S, et al. The association between dietary patterns, diabetes and depression. J Affect Disord. 2015;174:215-24.

21. Lim JH, Lee YS, Chang HC, Moon MK, Song Y. Association between dietary patterns and blood lipid profiles in Korean adults with type 2 diabetes. J Korean Med Sci. 2011;26(9):1201-8.

22. Mello VD, Laaksonen DE. Fibras na dieta: tendências atuais e benefícios à saúde na síndrome metabólica e no diabetes Mellitus tipo 2. Arq Bras Endocrinol Metabol. 2009;53(5):509-18.

23. Osonoi Y, Mita T, Osonoi T, Saito M, Tamasawa A, Nakayama $S$, et al. Relationship between dietary patterns and risk factors for cardiovascular disease in patients with type 2 diabetes Mellitus: A crosssectional study. Nutr J. 2016;15(15):15-11.

24. Noorshahi N, Sotoudeh G, Djalali M, Eshraghian MR, Karimi Z, Mirzaei K, et al. Healthy and unhealthy dietary patterns are related to lipid parameters in patients with type 2 diabetes Mellitus. J Nutr Health Sci. 2016;3:1-9.

25. Odegaard AO, Koh WP, Butler LM, Duval S, Gross MD, Yu MC, et al. Dietary patterns and incident type 2 diabetes in chinese men and women: The Singapore Chinese Health Study. Diabetes Care. 2011;34(4):880-5.

26. Morimoto A, Ohno Y, Tatsumi Y, Mizuno S, Watanabe $S$. Effects of healthy dietary pattern and other lifestyle factors on incidence of diabetes in a rural Japanese population. Asia Pac J Clin Nutr. 2012;21(4):601-8.

27. Satija A, Bhupathiraju SN, Rimm EB, Spiegelman $\mathrm{S}$, Chiuve SE, Borgi L, et al. Plant-based dietary 
patterns and incidence of type 2 diabetes in US men and women: Results from three prospective cohort studies. PLoS Med. 2016;13(6):1-18.

28. Shi Z, Zhen S, Zimmet PZZ, Zhou Y, Zhou Y, Magliano DJ, et al. Association of impaired fasting glucose, diabetes and dietary patterns with mortality: A 10-year follow-up cohort in Eastern China. Acta Diabetol. 2016;53(5):799-806.

29. Instituto Brasileiro de Geografia e Estatística. Pesquisa de Orçamentos Familiares (POF 2008-2009): análise do consumo alimentar pessoal no Brasil. Rio de Janeiro: IBGE; 2011.

30. Zad ND, Yusof RM, Mohseni F, Jamaluddin R, Esmaili $H$. Socio-demographic and lifestyle factors associated with dietary patterns among adults with type 2 diabetes Mellitus in Tehran, Iran. Int J Diabetes Dev Ctries. 2015;35(4):540-5.

Received: April 10, 2017

Final version: October 24, 2017

Approved: December 7, 2017 